\title{
Can Color Doppler Ultrasonography Differentiate Thyrotoxicoisis in Graves' Disease from Subacute Thyroiditis?
}

\author{
Anjuman Ara Akhter, Fariduddin M, Sharmin-Jahan, Nusrat-Sultana, Mashfiqul-Hasan, Atiqur-Rahman M, \\ Hasanat MA* \\ Department of Endocrinology, Bangabandhu Sheikh Mujib Medical University, Bangladesh
}

Submission: October 17, 2017; Published: December 20, 2017

*Corresponding author: Hasanat MA, Department of Endocrinology, Bangabandhu Sheikh Mujib Medical University (BSMMU), Shahbag, Dhaka-1000, Bangladesh, Tel: +880-1711670735; Email: hasanatdr@yahoo.com

\begin{abstract}
Background and objectives: Color flow Doppler (CFD) can determine thyroid vascularity. It can be used for confirmatory diagnosis of thyroiditis and Graves' instead of radioactive iodine uptake (RAIU). This study analysed thyroid blood flow, peak systolic velocity (PSV) by CFD and thyroid volume by Gray scale sonography in thyrotoxicosis.

Methods and materials: Thyrotoxic cases ( $N=78$; Graves: $M / F=21 / 27$, age: $35.73 \pm 1.38$; subacute thyroiditis: $M / F=09 / 21$, age: $35.37 \pm 1.61$ $(\mathrm{M} \pm \mathrm{SEM}, \mathrm{yrs})$ ) were recruited and divided into Graves' and subacute thyroiditis holding RAIU as gold standard. CFD and Gray scale sonography were done for all.

Results: Goiter was tender in $33 \%$ of subacute thyroiditis. Neither free thyroxine (FT4: $3.38 \pm 0.22$ vs. $2.78 \pm 0.23 \mathrm{ngm} / \mathrm{dl}, \mathrm{P}=0.549$ ) nor thyroid stimulating hormone (TSH: $0.05 \pm 0.01$ vs. $0.06 \pm 0.2 \mu \mathrm{IU} / \mathrm{ml}, \mathrm{P}=0.084$ ) were statistically different between the two groups. Echo pattern was predominantly homogeneous in Graves and heterogeneous in subacute thyroiditis ( $60.4 \%$ vs. $43.3 \%, \mathrm{P}=0.007)$. Gray scale sonography revealed increased thyroid volume in $73 \%$, normal in $20.8 \%$ and decreased in $6.3 \%$ of Graves which were $33.3 \%, 56.7 \%$ and $10.3 \%$ respectively in subacute thyroiditis ( $\mathrm{p}=0.002)$. All Graves' had increased flow while $76.7 \%$ of the subacute thyroiditis had decreased flow by CFD (P<0.001). Mean $( \pm$ SEM) PSV of inferior thyroid artery was significantly higher in Graves' than that of subacute thyroiditis $(40.70 \pm 2.54 \mathrm{vs} .26 .71 \pm 4.05 \mathrm{~cm} / \mathrm{sec}, \mathrm{P}=0.003)$ and correlated with RAIU at $2 \mathrm{~h}(\mathrm{r}=0.330, \mathrm{P}=0.003)$ and $24 \mathrm{hrs}(\mathrm{r}=0.325, \mathrm{P}=0.004)$ as well as blood flow $(\mathrm{r}=0.663, \mathrm{P}<0.001)$. Sensitivity and specificity of CFD were $93.7 \%$ \& $83.3 \%$ respectively.
\end{abstract}

Conclusion: It is concluded that CFD may be a cost effective, convenient, safe and noninvasive technique with high sensitivity, specificity and diagnostic accuracy.

Keywords: Color doppler ultrasonography; Graves' disease; Subacute thyroiditis

\section{Introduction}

Thyroid disease is common and the prevalence increases with age. It is one of the major health hazards in many countries including Bangladesh [1]. Thyrotoxicosis refers to the classic physiological manifestations of excessive quantities of thyroid hormone. Differentiation between hyperthyroid Graves' disease and destructive thyrotoxicosis in thyroiditis is very important for management purpose.

Radioactive iodine uptake (RAIU) is recognized as the most accurate test, but iodine-containing foods or drugs can interfere with the results. In addition, RAIU is expensive, not easily accessible and contraindicated during pregnancy and lactation [2]. On the other hand, color flow Doppler (CFD) is a useful, inexpensive, noninvasive and widely available. Its evaluation can be both qualitative (visual assessment of thyroid vascularity) and quantitative [measuring peak systolic velocity (PSV), end diastolic and mean velocities in the inferior thyroid arteries]. Normal PSV in intrathyroidal arteries ranges between 15 to $30 \mathrm{~cm} / \mathrm{sec}$ but it can rise to over $100 \mathrm{~cm} / \mathrm{sec}$ in certain pathologic conditions like Graves' disease [3]. CFD reveals a spectacular thyroid inferno with marked hypervascularity both in systole and diastole. Return of normal thyroid appearance may be possible during remission. Contrary to Graves' disease, vascularity is markedly diminished in subacute thyroiditis. In Graves disease, gray scale ultrasound reveals diffusely enlarged thyroid (2-3 times its normal size) which is hypoechoic and heterogeneous whereas in subacute thyroiditis it shows characteristic focal hypoechoic areas (map like) and enlargement of one or more lobes.

The aim of the study was to evaluate the utility of CFD in differentiation of hyperthyroid Graves' disease from subacute 
thyroiditis as well as comparing its sensitivity and specificity in light of RAIU test.

\section{Materials and Methods}

This study included 78 patients with thyrotoxicosis (Graves disease: $n=48, M / F=21 / 27$, age $(M \pm S E M, y r s): 35.73 \pm 1.38$; subacute thyroiditis: $n=30, M / F=09 / 21$, age $(M \pm S E M, y r s)$ : $35.37 \pm 1.61$ ) recruited from May 2014 to April 2015 in the department of Endocrinology, Bangabandhu Sheikh Mujib Medical University (BSMMU). Informed written consent was taken from all participants. Free thyroxine $\left(\mathrm{FT}_{4}\right)$, thyroid stimulating hormone (TSH) and RAIU and complete blood count with ESR were done for each subject. Thyroiditis and Graves' disease were discriminated on the basis of low versus high uptake. A color Doppler ultrasound scanner (Toshiba Ultrasonography system and color Doppler, Model no: SSA-550A, Toshiba medical system, Tokyo, Japan) equipped with a $7.5 \mathrm{MHz}$ broadband linear array high resolution transducer was used and both CFD and Gray scale ultrasound were performed at National Institute of Nuclear Medicine and Allied sciences (NINMAS), BSMMU campus. Thyroid blood flow was seen by color Doppler power mode. PSV of the inferior thyroid artery of $>30 \mathrm{~cm} / \mathrm{sec}$ was Table 1: Clinical findings in the participants $(n=78)$. considered significantly high and suggestive of Graves disease and $<30 \mathrm{~cm} / \mathrm{sec}$ for thyroiditis [3]. RAIU was considered as the gold standard. High RAIU was suggestive of Graves' disease and low RAIU considered for thyroiditis. All data were analyzed by SPSS (version 22.0).

\section{Results}

Though few clinical manifestations were statistically different between the two entities, altogether they were not conclusive (Table 1). Virtually all goiter of both the groups were diffuse $(p=N S)$. However, consistency of goiter was mostly soft in Graves' and firm in subacute thyroiditis $(\mathrm{p}<0.001)$. Similarly, tenderness was absent in Graves' disease except one case whereas $33 \%$ of subacute thyroiditis had tender goiter $(\mathrm{p}<0.001)$. FT4 in both Graves' and subacute thyroiditis were above the upper normal limit $(3.38 \pm 0.22$ and $2.78 \pm 0.23 \mathrm{ngm} /$ $\mathrm{dl}$ respectively, $\mathrm{m} \pm \mathrm{SEM} ; \mathrm{P}=0.549$ ) and TSH less than the lower limit $(0.05 \pm 0.01$ and $0.06 \pm 0.02 \mu \mathrm{IU} / \mathrm{ml}$ respectively, $\mathrm{P}=0.084)$. RAIU at 2 hrs $(21.35 \pm 1.43$ vs. $5.02 \pm 0.30$, mean \pm SEM; $\mathrm{P}<0.001)$ and at $24 \mathrm{hrs}(37.81 \pm 1.72$ vs. $2.94 \pm 0.35$, mean \pm SEM; $\mathrm{p}<0.001$ ) were higher in Graves' disease than that of subacute thyroiditis (Table 2).

\begin{tabular}{|c|c|c|c|}
\hline Variable & Graves' Disease $(n=48)$ & Sub Acute Thyroiditis $(n=30)$ & $\mathbf{P}$ \\
\hline Palpitation & $45(93.8 \%)$ & $23(76.7 \%)$ & 0.039 \\
\hline Weight loss & $42(87.5 \%)$ & $17(56.7 \%)$ & 0.003 \\
\hline Heat intolerance & $20.0(41.7 \%)$ & $04(13.3 \%)$ & 0.011 \\
\hline Hyper defecation & $08(16.7 \%)$ & $02(6.7 \%)$ & 0.301 \\
\hline Excessive Sweating & $34(70.8 \%)$ & $08(26.7 \%)$ & $<0.001$ \\
\hline Neck pain & $03(6.3 \%)$ & $23(76.7 \%)$ & $<0.001$ \\
\hline Fever & $04(8.3 \%)$ & $13(43.3 \%)$ & $<0.001$ \\
\hline Sore Throat & $04(8.3 \%)$ & $12(40.0 \%)$ & 0.001 \\
\hline Tremor & $24(50.0 \%)$ & $13(43.3 \%)$ & 0.644 \\
\hline Pulse (M \pm SEM,bpm) & $104 \pm 2$ & $98 \pm 2$ & 0.01 \\
\hline \multicolumn{4}{|l|}{ Goiter } \\
\hline Diffuse & $47(97.9 \%)$ & $30(100.0 \%)$ & 1 \\
\hline Nodular & $01(20.1 \%)$ & $00(0.0 \%)$ & \\
\hline \multicolumn{4}{|l|}{ Consistency } \\
\hline Soft & $36(75.0 \%)$ & $11(36.7 \%)$ & $<0.001$ \\
\hline Firm & $12(25.0 \%)$ & $19(63.3 \%)$ & \\
\hline Tenderness & $01(2.1 \%)$ & $10(33.3 \%)$ & $<0.001$ \\
\hline Bruit & $06(12.5 \%)$ & $01(3.3 \%)$ & 0.24 \\
\hline Eye Sign & 07 (14.6\%) & $00(0.0 \%)$ & 0.039 \\
\hline
\end{tabular}

Within parenthesis are percentages over column total. 
Table 2: RAIU in Graves' disease and subacute thyroiditis.

\begin{tabular}{|c|c|c|c|}
\hline RAIU & Graves Disease (n=48) & Subacute Thyroiditis (n=30) & P* \\
\hline $02 \mathrm{hr}($ Mean \pm SEM) & $21.35 \pm 1.43$ & $5.02 \pm 0.30$ & $<0.001$ \\
\hline $24 \mathrm{hr}($ Mean \pm SEM) & $37.81 \pm 1.72$ & $2.94 \pm 0.35$ & $<0.001$ \\
\hline
\end{tabular}

*by student's t-test.

RAIU: Radioactive lodine Uptake.

Echo pattern of thyroid was mostly homogeneous in Graves' $(60.4 \%)$ but heterogenous in subacute thyroiditis $(30.0 \%$; $\mathrm{p}=0.007)$. As observed by gray scale sonography, increased thyroid volume was found in $72.9 \%$ patients of Graves' disease whereas $6.3 \%$ had decreased and $20.8 \%$ had normal volume. On the contrary, in subacute thyroiditis $56.7 \%$ had normal, $33.3 \%$ increased, and $10.0 \%$ decreased volume ( $\mathrm{p}=0.002)$ (Table 3).

Table 3: Echo pattern in Gray Scale sonography.

\begin{tabular}{|c|c|c|c|}
\hline \multirow{2}{*}{ Echo Pattern } & \multicolumn{2}{|c|}{ Subjects } & \multirow{2}{*}{} \\
\cline { 2 - 3 } & $\begin{array}{c}\text { Graves } \\
\text { Disease } \\
(\mathbf{n = 4 8 )}\end{array}$ & $\begin{array}{c}\text { Subacute } \\
\text { Thyroiditis } \\
(\mathbf{n = 3 0 )}\end{array}$ & \multirow{2}{*}{$\mathbf{p}$} \\
\hline Homogeneous & $29(60.4 \%)$ & $09(30.0 \%)$ & \\
\hline Hyperechoic & $01(2.1 \%)$ & $01(3.3 \%)$ & $\chi 2=12.08$ \\
\hline Hypoechoic & $01(2.1 \%)$ & $07(23.3 \%)$ & $\mathrm{p}=0.007$ \\
\hline Heterogenous & $17(35.4 \%)$ & $13(43.3 \%)$ & \\
\hline
\end{tabular}

Within parenthesis are percentages over column total.

Cent percent of the Graves' disease subjects had increased blood flow by CFD. On the contrary, $76.7 \%$ of the subacute thyroiditis subjects had decreased flow, 16.7\% had increased flow and $6.7 \%$ had normal flow $(\chi 2=58.87, \mathrm{P}<0.001$ ) (Table 4). Mean $( \pm$ SEM) PSV of inferior thyroid artery was significantly higher in Graves' disease than that of subacute thyroiditis $(40.70 \pm 2.54$ vs. $26.71 \pm 4.05, \mathrm{P}=0.003)$. Considering $30 \mathrm{~cm} / \mathrm{sec}$ as cut off value, $93.8 \%$ of the Graves' subjects had PSV $>30 \mathrm{~cm} /$ sec; frequency of which was only $16.7 \%$ in subacute thyroiditis subjects ( $\mathrm{p}<0.001$ ) (Table 5). Doppler PSV strongly correlate with RAIU in both $2 \mathrm{~h}(\mathrm{r}=0.330, \mathrm{p}=0.003)$ and $24 \mathrm{hrs}(\mathrm{r}=0.325$, $\mathrm{p}=0.004$; Figure $1 \& 2$ ). PSV correlated with thyroid blood flow $(\mathrm{r}=0.663, \mathrm{p}<0.001)$ as well as thyroid volume $(\mathrm{r}=0.219, \mathrm{p}=0.054)$. Doppler thyroid blood flow was a strong predictor for diagnosis of Graves' disease and subacute thyroiditis ( $\mathrm{p}<0.001$ ); but none of the others were independently capable as predictor (Table 6).

Table 4: Thyroid blood flow by Color Flow Doppler Sonography.

\begin{tabular}{|c|c|c|c|}
\hline $\begin{array}{c}\text { Thyroid Blood } \\
\text { Flow }\end{array}$ & \multicolumn{2}{|c|}{ Subjects } & $\chi 2, \mathbf{P}$ \\
\hline & $\begin{array}{c}\text { Graves Disease } \\
(\mathrm{n}=48)\end{array}$ & $\begin{array}{c}\text { Subacute } \\
\text { Thyroiditis (n=30) }\end{array}$ & \\
\hline Increased & $48(100 \%)$ & $05(16.7 \%)$ & $\chi 2=58.87$ \\
\hline Normal & $00(0 \%)$ & $02(6.7 \%)$ & $\mathrm{P}<0.001$ \\
\hline Decreased & $0(0.0 \%)$ & $23(76.7 \%)$ & \\
\hline
\end{tabular}

Within parenthesis are percentages over column total.
Table 5: Peak systolic velocity (PSV) of inferior thyroid artery by color flow Doppler Sonography.

\begin{tabular}{|c|c|c|c|}
\hline PSV (cm/sec) & \multicolumn{2}{|c|}{ Subjects } & p \\
\hline & $\begin{array}{c}\text { Graves' Disease } \\
\text { (n=48) }\end{array}$ & $\begin{array}{c}\text { Subacute } \\
\text { Thyroiditis (n=30) }\end{array}$ & \\
\hline 30 or less & $03(6.3 \%)$ & $25(83.3 \%)$ & \\
\hline More than 30 & $45(93.8 \%)$ & $05(16.7 \%)$ & $<0.001$ \\
\hline Mean \pm SEM & $40.70 \pm 2.54$ & $26.71 \pm 4.05$ & 0.003 \\
\hline
\end{tabular}

by $\chi 2$ and student's t-test.

Within parenthesis are percentages over column total.

Table 6: Multiple Regressions analysis showing predictors for diagnosis of Graves' disease and subacute thyroiditis.

\begin{tabular}{|c|c|c|c|c|c|}
\hline $\mathbf{K i}$ & B & SE & Beta & $\mathbf{t}$ & p \\
\hline Constant & 1.197 & 0.613 & - & 1.953 & 0.057 \\
\hline Age & 0 & 0.005 & -0.009 & -0.104 & 0.917 \\
\hline Palpitation & -0.028 & 0.134 & 0.019 & 0.206 & 0.837 \\
\hline Weight loss & 0.035 & 0.1 & -0.033 & -0.351 & 0.727 \\
\hline Heat intolerance & 0.089 & 0.095 & -0.089 & -0.939 & 0.352 \\
\hline $\begin{array}{l}\text { Excessive } \\
\text { sweating }\end{array}$ & -0.072 & 0.091 & 0.077 & 0.794 & 0.431 \\
\hline Hyperdefaecation & -0.058 & 0.125 & 0.043 & 0.464 & 0.645 \\
\hline Tremor & -0.053 & 0.083 & 0.057 & 0.642 & 0.524 \\
\hline Goiter-Tender & 0.039 & 0.124 & -0.031 & -0.314 & 0.755 \\
\hline Exophthalmos & 0.13 & 0.151 & -0.074 & -0.863 & 0.392 \\
\hline FT4 & 0.003 & 0.003 & 0.009 & 0.092 & 0.927 \\
\hline TSH & 0.662 & 0.468 & 0.124 & 1.417 & 0.163 \\
\hline RAIU $2 \mathrm{~h}$ & 0.008 & 0.006 & 0.187 & 1.279 & 0.207 \\
\hline RAIU 24h & 0.001 & 0.004 & 0.04 & 0.224 & 0.824 \\
\hline $\begin{array}{l}\text { Doppler thyroid } \\
\text { volume }\end{array}$ & 0.002 & 0.038 & 0.004 & 0.048 & 0.962 \\
\hline $\begin{array}{l}\text { Doppler blood } \\
\text { flow }\end{array}$ & 0.352 & 0.073 & 0.671 & 4.834 & $<0.001$ \\
\hline
\end{tabular}

FT4: Free Thyroxine

TSH: Thyroid Stimulating Hormone 

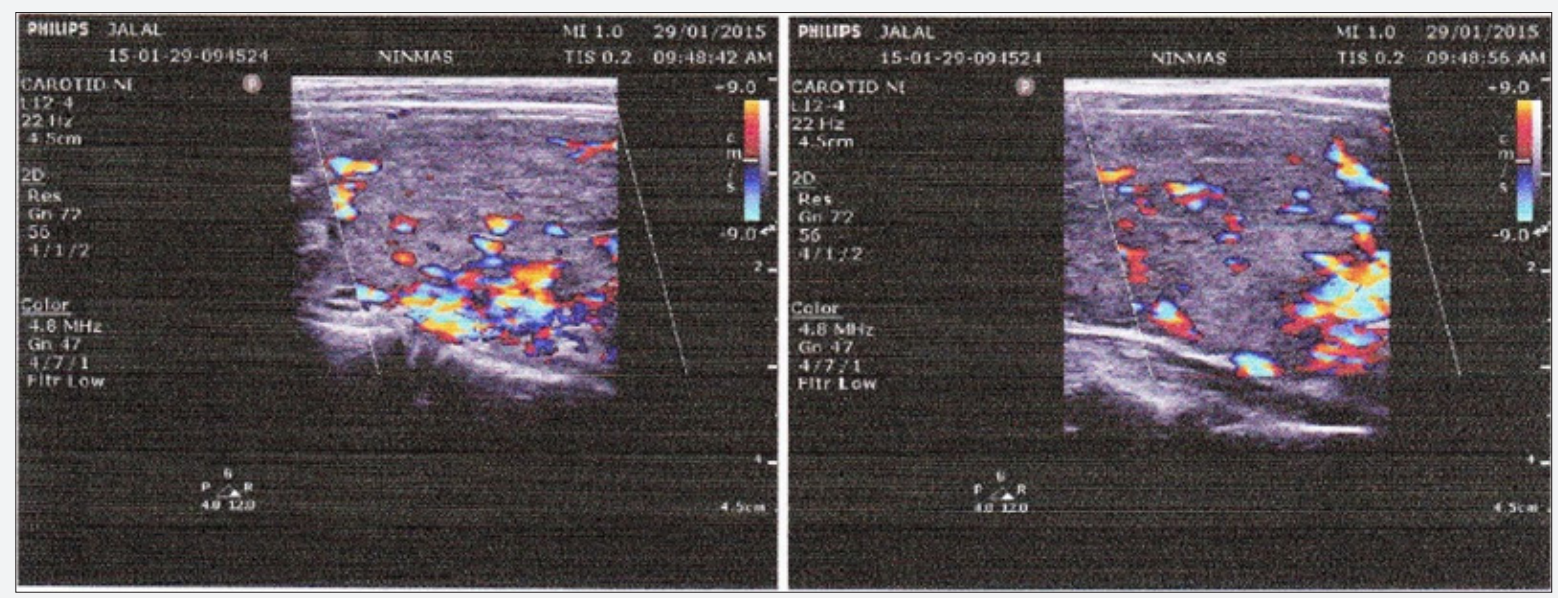

Figure 1: Color flow Doppler (CFD) reveals a spectacular thyroid inferno in a Graves' patient.

*Printed with permission from the patient.

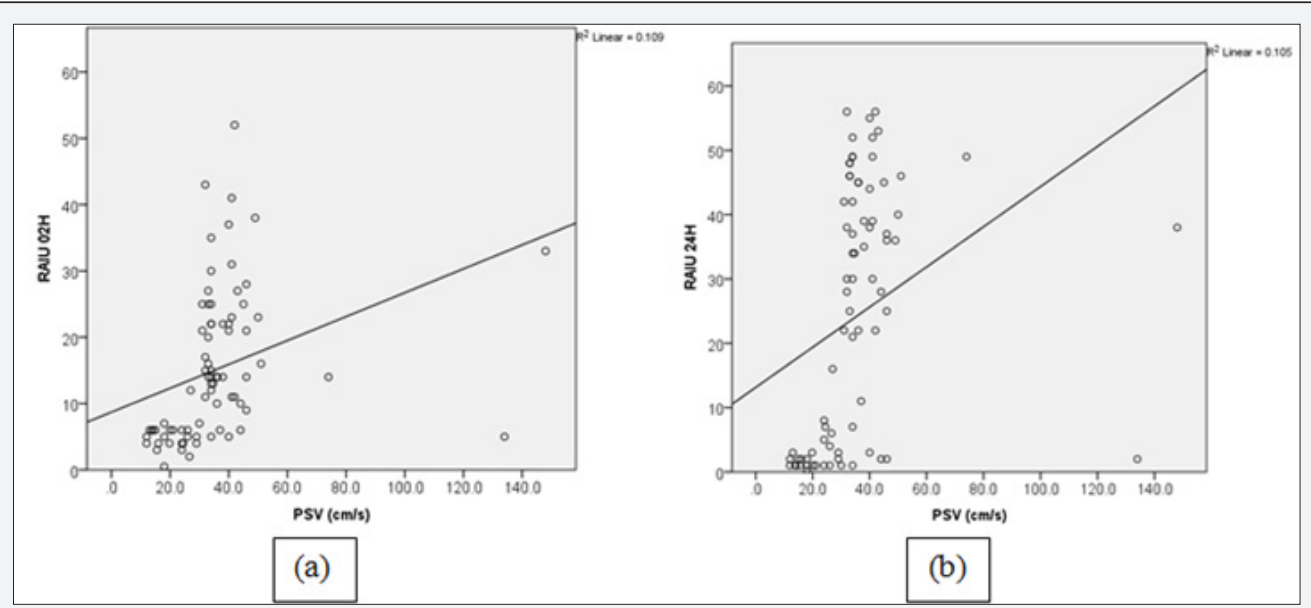

Figure 2: Correlation between peak systolic velocity (PSV) of inferior thyroid artery to (a) $2 \mathrm{~h}$ and (b) $24 \mathrm{~h}$ radioactive iodine uptake (RAIU) among the studied subjects.

Holding the RAIU as the gold standard for diagnosis of Graves' disease and subacute thyroiditis, sensitivity and specificity of CFD were $93.7 \%$ \& 83.3\% respectively. Positive predictive value was $90.0 \%$, negative predictive value was $89.2 \%$ and diagnostic accuracy was $89.7 \%$.

\section{Discussion}

In the present study, importance of relatively easily practicable, convenient and less hazardous modules like blood flow and PSV of inferior thyroid artery by CFD sonography and thyroid volume as well as echo pattern by gray scale sonography were investigated in the light of $2 \mathrm{~h}$ and $24 \mathrm{~h}$ RAIU as gold standard. It was clearly observed that cent percent of Graves' disease patient had increased thyroid blood flow in comparison to subacute thyroiditis in which more than three quarters showed decreased flow. Cut off value of $30 \mathrm{~cm} / \mathrm{sec}$ was considered in differentiation between Graves' disease from thyroiditis based on a review of relevant literature $[3,4]$. Our findings were in agreement with the findings of those investigators revealing more than $90 \%$ of the Graves' patient above the mentioned cut off while $80 \%$ of subacute cases were below.

Although echo pattern was found to be different, yet it was not enough to demarcate the two diseases- it was homogeneous in around $60 \%$ of Graves and $30 \%$ of subacute thyroiditis and by gray scale sonography $70 \%$ of Graves patient had increased volume while only $33 \%$ of subacute thyroiditis had so. Thus, neither echo pattern nor thyroid volume could be considered for diagnostic differentiation of the two disease status. Rather PSV was found to be free from performance related error and relatively better in distinguishing between the two diseases as well as less hazardous and easy practicable. Holding RAIU as the gold standard, sensitivity and specificity of PSV were $93.75 \%$ and $83.33 \%$ respectively with $89.7 \%$ diagnostic accuracy. The diagnostic performance is very satisfactory and in much agreement with other investigators' findings [5-8].

Though there are similarities of clinical manifestations between Graves' disease and thyroiditis, it was observed in this 
study that some clinical manifestations like palpitation, weight loss, heat intolerance, hyperdefaecation, excessive sweating, tremor were more prominent in Graves' than subacute thyroiditis whereas neck pain/ tenderness, fever, sore throat were more prominent in subacute thyroiditis as was expected. $75 \%$ of the goiter was soft in Graves' disease while in subacute thyroiditis $63 \%$ were firm in consistency. Bruit $(12.5 \%)$ and eye sign $(14.6 \%)$ were exclusively seen in patients with Graves'. None of the abovementioned features could clearly distinguish between these two groups as features of thyrotoxicosis overlapped in both the groups.

CFD is a cheap and simple technique with no ionizing radiation exposure and is cost effective in the diagnosis of thyrotoxicosis. A typical CFD thyroid examination takes about 10 minutes [9]. Inferior thyroid artery blood flow could be considered as an acceptable alternative to RAIU test especially when there is a contraindication to nuclear imaging of the thyroid. Radioactive iodine should not be used in situations with recent use of iodinated contrast which interfere with the accuracy of radioactive iodine tests [9]. Phillips et al. found that $45 \%$ of patient with newly diagnosed thyrotoxicosis had received iodinated contrast within 2 week before endocrine evaluation for other purposes heralding diagnostic difficulty [10]. Therefore, in these scenario if some diagnostic module avoiding the use of radioisotope can be utilized diagnostic difficulties can be overcome. In such context, we might propose and would fully agree with other investigators [11,12] supporting diagnostic modules like PSV by CFD to discriminate between thyrotoxicosis due to Graves' and subacute thyroiditis.

In summary, the thyroid blood flow is a useful marker in diagnosis of Graves' disease and subacute thyroiditis in initial phase. The high correlation between RAIU and PSV by CFD established this modality as an acceptable alternative. Its role in pregnancy and lactation where nuclear imaging is contraindicated needs to be emphasized. Data of present study suggest that CFD may be a cost effective, quick, safe and noninvasive technique in contrast to RAIU with high sensitivity, specificity and diagnostic accuracy.

\section{References}

1. Chakraborty I, Mazumdar P, Chakraborty PS, Chattopadhyay G, Bhowmik K (2010) Iodine deficiency disorder among pregnant women in a tertiary care hospital of Kolkata, India. Southeast Asian J Trop Med Public Health 41(4): 989-995.

2. Chen, Zhao X, Liu H, Wang Y, Li L, et al. (2012) Mean Peak systolic Velocity of the Superior Thyroid Artery is Correlated with Radioactive Iodine Uptake In Untreated Thyrotoxicosis. J Int Med Res 40(2): 640647.

3. Santos TARRD, Pina ROG, Souza MTPD, Chammas MC (2014) Graves' Disease Thyroid Color-Flow Doppler Ultrasonography Assessment: Review Article. Scientific Research 6(12): 1487-1496.

4. Sipos JA, Kahaly GJ (2012) Imaging of Thyrotoxicosis. Am J Med 125: 1-3.

5. kurita S, Sakurai M, Kita Y, Ota T, Takamura T (2005) Measurement of thyroid blood flow area is useful for diagnosing the cause of thyrotoxicosis. Thyroid 15(11): 1249-1252.

6. Kumar HKV, Pasupuleb V, Jayaraman M, Abhyuday V, Rayudu B, et al. (2009) Role of thyroid Doppler in differential diagnosis of Thyrotoxicosis. Endocr Pract 15(1): 6-9.

7. Bogazzi F, Vitti P (2008) Could improved ultrasound and power Doppler replace thyroidal radioiodine uptake to assess thyroid disease. Nat Clin Pract Endocrinol Metab 4(2): 70-71.

8. Nagasaki T, Inaba M, Kumeda Y, Fujiwara UM, Hiura, et al. (2007) Significance of thyroid blood flow as a predictor of methimazole sensitivity in untreated hyperthyroid patients with Graves disease. Biomed Pharmacother 61(8): 472-476.

9. Ralls PW, Mayekawa DS, Lee KP, Colleti PM, Radin DR, et al. 1988. ColorFlow Doppler Sonography in Graves Disease: "Thyroid inferno". AJR Am J Roentgenol 150(4): 781-784.

10. Phillips BS, Hennessey JV (2009) Iodinated contrast prior to evaluation for thyrotoxicosis. J Hosp Med 4(5): 285-288.

11. Ota H, Amino N, Morita S, Kobayashi K, Kubota S, et al. (2007) Quantitative measurement of thyroid blood flow for differentiation of painless thyroiditis from Graves disease. Clin Endocrinol 67(1): 41-45.

12. Kumar H KVS, Vamsikrishna P, Verma A, Mutukrishna J, Rayudu BR, et al. (2009. Utility of Colour Doppler Sonography in Patients with Graves' Disease. West Indian Med J 58(6): 566-570.

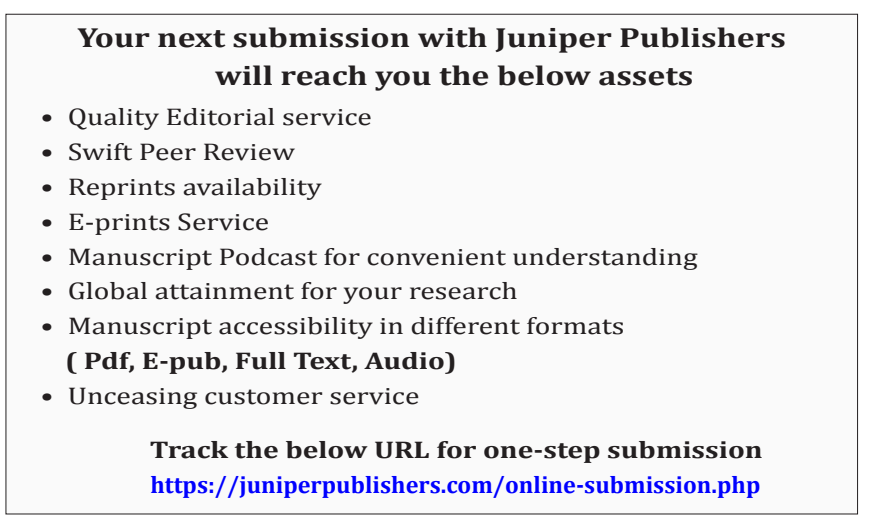

